\title{
Indoor air quality in natural-ventilated bedrooms in renovated Norwegian houses
}

\author{
Vegard Heide, Silje Skyttern, and Laurent Georges \\ Department of Energy and Process Engineering, Faculty of Engineering, NTNU, Trondheim, Norway
}

\begin{abstract}
The objective of this work is to investigate the indoor environment in bedrooms ventilated by window opening during night-time. How window opening behaviour affects indoor air quality (IAQ), and how window opening behaviour and IAQ is influenced by external factors, are important questions. The context is renovation of detached wooden houses in Norway. To motivate building owners to renovate their ventilation system, it is important to know the typical indoor environment in bedrooms of existing buildings with natural ventilation. Ten bedrooms in six case houses were investigated by measuring temperature, relative humidity, $\mathrm{CO}_{2}$, particulate matter, formaldehyde and TVOC. The window opening angle was also logged with an accelerometer. The measurements were conducted over 2 to 3 weeks, during March and April. The dwellings were renovated single-family and terraced houses from $1950-80$, in Trondheim. All the bedrooms had natural ventilation, and the occupants stated they used to open bedroom windows at night. Participants answered a questionnaire about motivations and habits regarding window opening. The most common reason given for not opening was low outdoor temperatures. The window opening behaviour was both predictable and continuous. Windows were open every night in most of the bedrooms, and most of the windows were opened to the same position every night. High $\mathrm{CO}_{2}$ levels during night were found in two bedrooms. In the other bedrooms, the $\mathrm{CO}_{2}$ concentration was satisfying during night-time, although higher concentrations were found in some bedrooms during daytime. Finally, indoor temperature measurements confirmed that many occupants prefer a low bedroom temperature.
\end{abstract}

\section{Introduction/background}

The scope of this research is renovation of detached wooden houses with a strong focus on user behavior in Norway. Small wooden dwellings are responsible for more than half of the total energy use in the Norwegian building stock. A recent study found that $60 \%$ of the Norwegian detached households made no changes to the ventilation system when performing an energy renovation, while only $9 \%$ installed balanced mechanical ventilation. However, renovation usually includes a substantial improvement in airtightness of the building envelope. This reduces the air change due to infiltration, demanding specific ventilation measures to provide sufficient indoor air quality (IAQ). Opening bedroom windows at night is a common method to perform natural ventilation. Many people accept, and prefer, lower temperatures in bedrooms than in other parts of the home [1-3].

The objective of this study was to investigate IAQ in window-ventilated bedrooms in renovated houses. Important questions were whether a satisfying indoor environment can be achieved in bedrooms by opening the window during nighttime, and whether people actually make the window opening area large enough for sufficient air change.

Bedroom are often small rooms where occupants spend many hours, often with the door closed. Although almost one third of people's life is spent in bedrooms, there are not many field studies monitoring IAQ in bedrooms. Very few studies have measured diurnal and weekly fluctuations, and investigated the relationship between IAQ and window opening behaviour over these time scales $[4,5]$.

Installing balanced mechanical ventilation in an existing building may be challenging or expensive. Therefore, it is important to better understand the performance and limitations of natural ventilation in bedrooms. With good IAQ, these bedrooms could be left out of the balanced mechanical ventilation system and lead to simpler installations. With poor IAQ, the study may increase the motivation in investing in a (more expensive) balanced mechanical ventilation.

\subsection{Indoor air quality (IAQ)}

Measured $\mathrm{CO}_{2}$ concentration is a common indicator of the air quality, but is not itself regarded as a hazardous component. In general, $\mathrm{CO}_{2}$ concentrations of $1000 \mathrm{ppm}$ is used as a threshold value [6]. The standard EN16798, which considers energy performance and ventilation in buildings, operates with four different categories for IEQ, corresponding to different $\mathrm{CO}_{2}$ concentrations [7]

Several studies report low air change rates $(\mathrm{ACH})$ and high levels of IAQ parameters. Øie et al. [8] investigated the air change rate of 344 residences located in Oslo in 1988 during a fourteen-day period. The total air change rate was measured with a passive tracer gas method, and showed that $36 \%$ of the residences had a lower air change rate than the national requirement $(0.5 / \mathrm{h})$. The studied dwellings included 
apartments and single-family houses with both mechanical exhaust and natural ventilation.

Langer et al. [9] made a similar investigation in 157 single-family houses and 148 apartments in Sweden during the heating season in 2013. The mean air change rate was shown to be $0.37 / \mathrm{h}$ in the single-family houses, and $0.5 / \mathrm{h}$ in the apartments. This resulted in $85 \%$ of the single-family houses having an air change rate below $0.5 / \mathrm{h}$, and $74 \%$ for the apartments. The results indicated that the buildings with natural ventilation had lower air change rates than those with mechanical ventilation.

The concentration of TVOC and formaldehyde was also investigated in the same study. The median concentrations found in this study were lower than the guideline values for formaldehyde suggested by WHO [10]. Langer also found a negative correlation between the air change rate and the two pollutants.

\subsection{Bedrooms, $\mathrm{ACH}$ and $\mathrm{IAQ}$}

Bornehag et al [11] found similar ACH investigating children's bedroom of 390 Swedish homes in 2005. The bedrooms in the single-family houses had a mean ventilation rate of $0.36 / \mathrm{h}$, while the mean rate was measured to be $0.48 / \mathrm{h}$ in the apartments. Like Øie, Bornehag also found higher ventilation rates in the single-family houses with mechanical exhaust and supply ventilation, compared to those with natural ventilation. A passive tracer gas method was used, with a duration of one week.

Bekö et al. [12] investigated the bedrooms of 500 Danish children in 2010. The measuring period was only 2 days and 2 nights between March and May 2008. The $\mathrm{CO}_{2}$ concentration was measured during night-time and the $\mathrm{ACH}$ estimated by a single-zone mass balance model. The opening of windows and doors was logged by the parents. The results showed that $57 \%$ of the bedrooms had air change rates of less than $0.5 / \mathrm{h}$. The study also indicated that the air change rate increased together with the occupant number, assuming more frequent window opening at higher occupancy. The windows were, however, closed both nights in $80 \%$ of the rooms. $33 \%$ of the bedrooms experienced a 20 minute period where the average $\mathrm{CO}_{2}$ level was above $2000 \mathrm{ppm}$ and $6 \%$ where the concentration was above $3000 \mathrm{ppm}$.

Other studies have also found high $\mathrm{CO}_{2}$ levels in bedrooms during night-time. Kotol et al. investigated the indoor environment in 79 residences with natural ventilation in Greenland, for a period of seven days [13]. In $66 \%$ of the bedrooms the average night concentration exceeded $1000 \mathrm{ppm}$ in winter. $46 \%$ of the bedrooms experienced 20-minute periods with $\mathrm{CO}_{2}$ concentration exceeding 2000 ppm.

Aubin et al. investigated 115 Canadian homes, using the Perfluorocarbon Tracer (PFT) technique [14]. In winter and fall, $85 \%$ of the homes did not achieve the nominal air change rate of $0.30 / \mathrm{h}$. The 24 -hour averaged $\mathrm{CO}_{2}$ concentrations in bedrooms were $1024 \mathrm{ppm}$. Formaldehyde and VOC was also measured using passive sampling, and showed more pollution when lower ACR.

Sharpe et al. measured bedroom conditions in 26 low-energy houses in Scotland, with both balanced and natural ventilation [15]. $\mathrm{CO}_{2}$ levels in February were consistently above $1000 \mathrm{ppm}$ in $62 \%$ of the bedrooms with natural ventilation. All but three of the bedrooms have some periods above $1000 \mathrm{ppm}$. CO2-levels were generally lower during summer.

Shinohara et al studied 26 Japanese bedrooms across the whole season, with the use of PFT technique in $\mathrm{NV}+\mathrm{MV}$ [16]. The mean $\mathrm{ACH}$ in the bedrooms was 1.3 in summer, 0.49 in autumn, 0.38 in winter, 0.84 in spring and 1.4 the following summer.

Fernandez-Aguera et al. measured indoor air quality in 3 case houses with natural ventilation in Spain. The typical median levels of $\mathrm{CO}_{2}$ in bedrooms ranged between 1199 and 2385 ppm. [5].

A study in Estonia involving 88 bedrooms with different ventilation strategies, used the night-time occupant generated $\mathrm{CO}_{2}$ to calculate $\mathrm{ACH}$. Results showed a mean bedroom air change rate of $0.6 / \mathrm{h}$, and mean air change rate of $0.32 / \mathrm{h}$ for the whole building, during winter [17].

Several studies on bedrooms have found seasonal dependence of ACHs and some of the IAQ measurements, with higher concentrations in winter or fall $[5,14-16,18,19]$. However, Bekø [12] did not find any correlation between outdoor temperature and ventilation rate during their ten-week long measurements in Danish bedrooms. One study reported a correlation between low infiltration and high $\mathrm{CO}_{2}$ level [5]. Some studies also reported higher $\mathrm{ACH}$ or lower $\mathrm{CO}_{2}$ concentrations in bedrooms than the living rooms or the rest of the apartment [5, 17-19], but others the opposite [20].

Some studies show rather high $\mathrm{CO}_{2}$ levels also in bedrooms using balanced ventilation. Berge and Mathisen found that 2 out of 7 measured bedrooms exceeded $1200 \mathrm{ppm}, 5$ and $6 \%$ of the night-time [2]. Corresponding levels were reported in a Swedish study, where air quality was investigated in 20 new passive houses and 21 conventional new houses. The average $\mathrm{CO}_{2}$ level in the bedrooms exceeded $1000 \mathrm{ppm} 6 \%$ of the time in the passive houses and $10 \%$ of the time in the conventional houses during the two-week measuring period [21].

In conclusion, although the number of studies is limited, they suggest that the IAQ is not sufficient in a large fraction of the bedrooms with natural ventilation.

\subsection{Window opening behaviour}

A Norwegian survey by Bjorvatn et al. in 2017 [1] reported that about $30 \%$ of the 1001 respondents always sleep with the bedroom window open. The percentage increases with increasing age. Andersen et al. [4] investigated the window opening behaviour in Danish dwellings, and found window openings most common in bedrooms, particularly the main bedroom. He also found that $\mathrm{CO}_{2}$ concentration and outdoor temperature 
correlates with the opening of windows. Closing behaviour relates to low indoor and outdoor temperature. RH seemed to correlate to both opening and closing. Jones et al. [22] monitored 10 dwellings in UK and also found a correlation between window closing and both windspeed and rainfall. Bekø et al. [12] found that, for bedrooms, the driver to open windows is to obtain fresh air and not to control the indoor temperature. However, in the work of Berge et al. in highly-insulated buildings with balanced ventilation, a survey showed that the main motivation to open windows was temperature regulation. [23].

Verbruggen et al. [24] investigated window opening in Belgium. They found that many occupants follow habits regarding window openings, indicating that the window use is less related to the environmental variables. Most occupants have specific behaviours in the different rooms, especially in the bedroom (97\%). Many open or close windows when going to bed, and getting up, while more than $10 \%$ leaves the bedroom windows always open in wintertime (also in houses with balanced ventilation). This increases to $37 \%$ in summer. Sharpe et al. observed window opening being more prevalent in the summer [15].

Levie et.al made a survey on ventilation behaviour during heating season in Netherlands (with 4534 responses). They found clear differences in window opening behaviour in different rooms. For bedrooms, $90 \%$ of the respondents report to ventilate at least $1 \mathrm{~h}$ per week, $60 \%$ more than $7 \mathrm{~h}, 50 \%$ more than $14 \mathrm{~h}$ and $30 \%$ more than $56 \mathrm{~h}$ per week. In general, bedrooms were ventilated considerably more than the living room during the heating season. Occupants of houses with better insulation, seemed to have windows or doors opened for a longer period.

In conclusion the literature shows large differences of user behaviour regarding window openings. In many studies, the window openings appear to be more frequent in bedrooms than the other rooms. Window openings also seem to follow the culture and habits. In that respect, Norwegians use window openings extensively in bedrooms.

\subsection{Bedroom temperature}

Several studies have shown that many occupants accept or prefer low bedroom temperatures. A Norwegian survey by Bjorvatn reported that about $32 \%$ of the 1001 respondents prefer a bedroom temperature below $12^{\circ} \mathrm{C}$, and approximately $38 \%$ prefer a temperature between $13-17^{\circ} \mathrm{C}$ during the heating season. [1]. The desire for cool bedrooms is also shown in Denmark by measurements in bedrooms after renovation [3] [25].

Liu et al. [26] found that that occupants in China's hot summer and cold winter region have a very strong tolerance to low temperatures in bedrooms: $80 \%$ of occupants regarded the acceptable lower temperature to be as low as $4.7^{\circ} \mathrm{C}$ and the neutral temperature was found to be $10.7^{\circ} \mathrm{C}$. However, Sharpe et al. observed high temperature in UK bedrooms and concluded that "it would seem that the notion of a bedroom as a cooler space, used infrequently, is outdated' [15]. These studies show that preferences vary between countries, due to differences in culture, buildings and heating systems. Bedrooms used only for sleeping, equipped with highly insulating duvets may induce tolerance for lower temperatures and for draught from open windows.

\subsection{Research questions}

The literature review showed that the IAQ in naturally ventilated bedrooms was lower than the standard requirements in a significant fraction of the buildings. However, the literature showed different habits and culture regarding indoor environment and window openings in bedrooms. In particular, the use of window openings and preference for low bedroom temperatures are more pronounced in Norway. Consequently, it is necessary to investigate the IAQ of natural-ventilated bedrooms in the specific case of Norway. The main research questions are to:

- Evaluate the indoor environmental quality in bedrooms with natural ventilation in renovated detached houses.

- Determine whether a satisfying IAQ can be ensured in bedrooms by window opening during night-time.

Complementary questions are:

- How does the window opening behaviour affect IAQ?

- How the window opening behaviour is influenced by external factors?

\section{Method}

Ten bedrooms in six different case houses were investigated by measuring temperature, $\mathrm{RH}, \mathrm{CO}_{2}$, particulate matter (PM), TVOC and formaldehyde (FH). The window opening angle was also logged with an accelerometer. The measurements were conducted over 2 to 3 weeks, during March and April 2020. In addition, participants answered a questionnaire about their motivation and habits regarding window opening. All the bedrooms had natural ventilation. All occupants stated that they used to open bedroom windows during nighttime. Weather data was collected from a weather station located 1 to 5 kilometres away, using the Norwegian Metrological Institute database [27]. More detailed information regarding the measurement setup and results are described in Skyttern [28].

\subsection{Description of the case houses}

Every building had 2 floors and are constructed in wood. The test cases are either detached or row-houses. They were recently renovated, thus indicating a lower infiltration rate. All buildings are located in the Trondheim area, with a semi-coastal, cold climate. 
Table 1. Overview of window characteristics of the bedrooms

\begin{tabular}{|c|c|l|l|c|c|}
\hline $\begin{array}{c}\text { Case } \\
\text { house }\end{array}$ & $\begin{array}{l}\text { Bed- } \\
\text { room }\end{array}$ & $\begin{array}{l}\text { Wind. } \\
\text { hinge }\end{array}$ & $\begin{array}{l}\text { Wind.size } \\
\mathrm{H} \times \mathrm{W}\end{array}$ & $\begin{array}{l}\text { Occ. } \\
\text { numb }\end{array}$ & Type of curtain \\
\hline \multirow{2}{*}{ H1 } & B1 & Top- & $0.34 \times 1.25$ & 2 & Heavy (closed) \\
\cline { 2 - 6 } & B2 & Top- & $1.1 \times 1$ & 1 & Dropdown (open) \\
\cline { 2 - 6 } & B3 & Top- & $1.1 \times 1$ & 1 & Dropdown (closed) \\
\hline H2 & B1 & Top- & $1 \times 0.95$ & 1 & Plissè (closed) \\
\cline { 2 - 6 } & B2 & Top- & $1 \times 0.95$ & 1 & Light (closed) \\
\hline H3 & B1 & Side- & $1.4 \times 0.47$ & 1 & Heavy (closed) \\
\cline { 2 - 6 } & B2 & Middle & $0.6 \times 0.45$ & 1 & - \\
\hline H4 & B1 & Side- & $1.1 \times 0.45$ & 1 & - \\
\hline H5 & B1 & Side- & $1.2 \times 0.3$ & 1 & Light (semi-closed) \\
\hline H6 & B1 & Top- & $0.45 \times 0.8$ & 2 & - \\
\hline
\end{tabular}

\subsection{Selection of buildings and inhabitants}

To identify suitable houses, building companies and associations have been contacted, as well as the personal network of the authors. This study targets inhabitants who claim to use window ventilation in bedrooms. Therefore occupants stating they usually open the bedroom window when sleeping have been asked to participate. The buildings were mainly renovated, without mechanical ventilation, and with a relatively airtight envelope. Therefore, the case buildings may not be representative for all Norwegian dwelling.

\subsection{Logging instruments}

For the IAQ measurements, an Arduino-based noncommercial rig was used based on the following sensors: SCD30 $\left(\mathrm{CO}_{2}, \mathrm{~T}^{\circ}, \mathrm{RH}\right), \mathrm{WZ}-\mathrm{S}(\mathrm{FH}), \mathrm{SPS} 30$ (PM), SGP30 (TVOC), SVM30 (TVOC, T ${ }^{\circ}$ RH) and SHTC1 $\left(\mathrm{T}^{\circ}, \mathrm{RH}\right)$. The movable rig was tested and described by Gram [29], and Berg Jørgensen [30]. These sensors were calibrated and tested for $\mathrm{CO}_{2}$, temperature, $\mathrm{RH}$ and PM, with a Pegasor $A Q$ Indoor measuring instrument as reference.

\subsection{Window opening sensors}

Previous studies on window opening behaviour have mostly recorded open or closed states while the area of the opening has hardly been monitored. To be able to investigate the relation between the degree of window opening and IAQ, a sensor measuring the window opening angle was developed in the project. This was based on a BBC micro:bit. This is a small, lightweight codable computer that is used for educational purposes in schools [31]. Due to its small size and light weight, it can easily be mounted on the window frame with double-sided tape. It has a built-in accelerometer and magnetometer as well as a flash memory and is easily programmable in Arduino. The micro:bit can also communicate with other devices via Bluetooth. In our case, the data was stored on a Raspberry Pi located in the same room. Accuracy was tested to be 2 degrees.

During the installation of the equipment, the size and shape of the windows, and the thickness and extension of curtains were registered. Information about the curtain position and habits was also a part of the questionnaire.

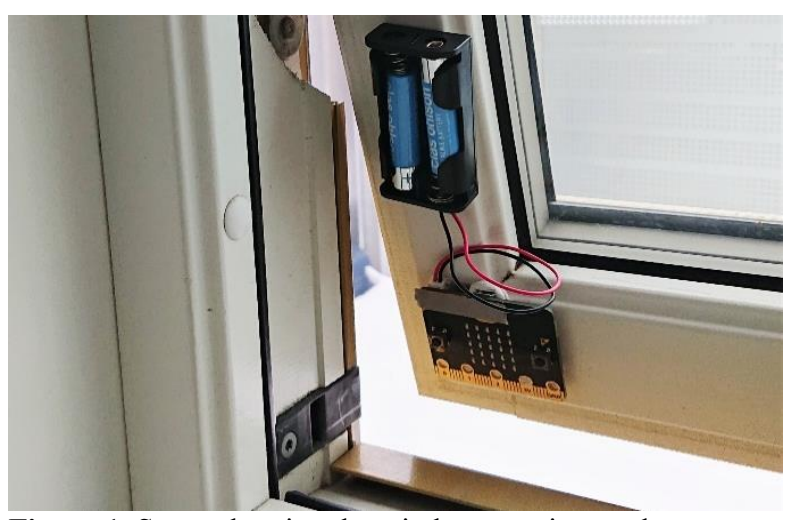

Figure 1. Sensor logging the window opening angle.

\section{Results}

\subsection{Questionnaire}

All the participants in the questionnaire answered that fresh air was a main motivation to open the bedroom window at night. Three out of six houses answered that lowering the bedroom temperature was also part of the motivation. However, low temperature was also the most common reason given for not opening windows.

Table 2. Results of the questionnaire:

\begin{tabular}{|c|c|c|c|c|c|c|c|c|}
\hline $\begin{array}{c}\text { Case } \\
\text { house }\end{array}$ & $\begin{array}{c}\text { Bed } \\
\text { room }\end{array}$ & \multicolumn{2}{|c|}{$\begin{array}{c}\text { Motivation for opening } \\
\text { window at night }\end{array}$} & \multicolumn{4}{c|}{$\begin{array}{c}\text { Motivation for not opening } \\
\text { window at night }\end{array}$} \\
\hline & & Fresh air & $\begin{array}{c}\text { Lower } \\
\text { bedr. temp }\end{array}$ & Habit & $\begin{array}{c}\text { Outdoor } \\
\text { temp }\end{array}$ & $\begin{array}{c}\text { Outside } \\
\text { noise }\end{array}$ & $\begin{array}{c}\text { Cold in } \\
\text { bedroom }\end{array}$ & Forget \\
\hline \multirow{3}{*}{ H1 } & B1 & $x$ & $x$ & & $x$ & & & \\
\cline { 2 - 10 } & B2 & $x$ & $x$ & & & & & $x$ \\
\cline { 2 - 10 } & B3 & $x$ & $x$ & $x$ & & & & $x$ \\
\hline \multirow{2}{*}{ H2 } & B1 & $x$ & $x$ & & $x$ & & $x$ & \\
\cline { 2 - 10 } & B2 & $x$ & & & & & $x$ & \\
\hline H3 & B1 & $x$ & $x$ & & & & & \\
\hline H4 & B1 & $x$ & & & & & $x$ & \\
\hline H5 & B1 & $x$ & & & & $x$ & & \\
\hline
\end{tabular}

\subsection{Window opening behaviour}

Results show that windows were open every night in most of the bedrooms. Most of the windows were opened to the same position each night. Figure 2 shows that windows in house1, bedroom1 (H1B1) and house3, bedroom 2 (H3B2), were open both day and night. The size of the opening was small, however.

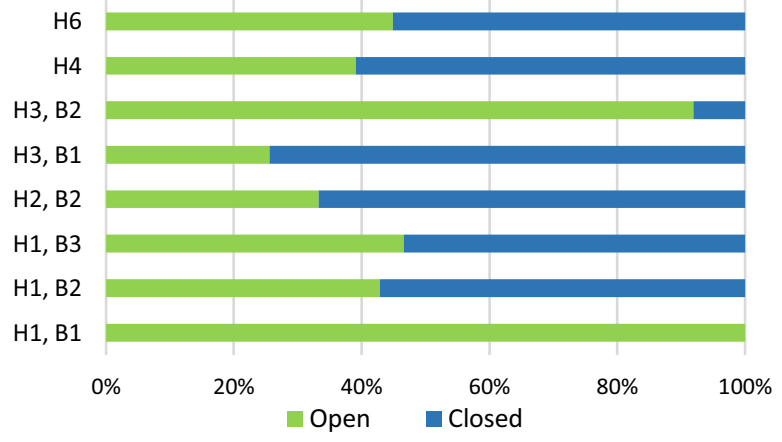

Figure 2. Window opening duration during the whole period

The average window opening area is shown in table 3. A low standard deviation indicates that the window is opened to the same position each night. The smallest 
average opening area was found in $\mathrm{H} 3 \mathrm{~B} 2$ and was significantly smaller than in the other rooms. However, the airflow in the open area is expected to be large for this window, as it is a middle-hinged skylight. This allows incoming air in the lower opening, and leaving air in the upper opening.

Table 3. Time-averaged window opening area during nighttime: mean and standard deviation in brackets (SD)

\begin{tabular}{|c|c|l|c|c|}
\hline $\begin{array}{c}\text { Case } \\
\text { house }\end{array}$ & $\begin{array}{c}\text { Bed } \\
\text { room }\end{array}$ & Type of window & $\begin{array}{c}\text { Average. window opening } \\
\text { area [m2] (SD) }\end{array}$ & $\begin{array}{c}\text { Wind.size } \\
\mathrm{H} \times \text { W }\end{array}$ \\
\hline \multirow{3}{*}{ H1 } & B1 & Top-hinged & $0.15(0.00)$ & $0.34 \times 1.25$ \\
\cline { 2 - 5 } & B2 & Top-hinged & $0.13(0.01)$ & $1.1 \times 1$ \\
\cline { 2 - 5 } & B3 & Top-hinged & $0.10(0.01)$ & $1.1 \times 1$ \\
\hline \multirow{2}{*}{ H2 } & B1 & Top-hinged & $0.09(0.01)$ & $1 \times 0.95$ \\
\cline { 2 - 5 } & B2 & Top-hinged & $0.08(0.01)$ & $1 \times 0.95$ \\
\hline \multirow{2}{*}{ H3 } & B1 & Side-hinged & $0.15(0.06)$ & $1.4 \times 0.47$ \\
\cline { 2 - 5 } & B2 & Middle, skylight & $0.01(0.00)$ & $0.6 \times 0.45$ \\
\hline H4 & B1 & Side-hinged & $0.11(0.06)$ & $1.1 \times 0.45$ \\
\hline H5 & B1 & Side-hinged & & $1.2 \times 0.3$ \\
\hline H6 & B1 & Top-hinged & $0.06(0.01)$ & $0.45 \times 0.8$ \\
\hline
\end{tabular}

\section{$3.3 \mathrm{CO}_{2}$ levels}

Only the measurements between 23:00 and 06:00 have been included in the nightly averaged calculations, and nights without occupancy have been disregarded. In addition, the night with the lowest and highest average concentrations are presented, referred to as minimum and maximum averages. The time-averaged $\mathrm{CO}_{2}$ concentration during night-time exceeded $1000 \mathrm{ppm}$ in H1B1 and in H3B2. The latter was also where the highest maximum nightly average was measured at approximately $1850 \mathrm{ppm}$.

Table 4. Time-averaged night-time $\mathrm{CO}_{2}$ concentration.

\begin{tabular}{|c|c|c|c|c|c|c|}
\hline $\begin{array}{c}\text { Case } \\
\text { house }\end{array}$ & $\begin{array}{c}\text { Bed- } \\
\text { room }\end{array}$ & $\begin{array}{c}\text { Av. CO2 } \\
{[\mathrm{ppm}](\mathrm{SD})}\end{array}$ & $\begin{array}{c}\text { Min. av. } \\
\text { CO2 } \\
{[\mathrm{ppm}]}\end{array}$ & $\begin{array}{c}\text { Max. av. } \\
\text { cO2 } \\
{[\mathrm{ppm}]}\end{array}$ & $\begin{array}{c}\text { Av. Window } \\
\text { opening area } \\
{[\mathrm{m} 2](\mathrm{SD})}\end{array}$ & $\begin{array}{c}\text { Window } \\
\text { area } \\
{[\mathrm{m} 2]}\end{array}$ \\
\hline \multirow{3}{*}{$\mathrm{H} 1$} & $\mathrm{~B} 1$ & $1097(232)$ & 901 & 1303 & $0.15(0.00)$ & 0.4 \\
\cline { 2 - 8 } & B2 & $532(89)$ & 439 & 657 & $0.13(0.01)$ & 1.1 \\
\cline { 2 - 8 } & B3 & $733(130)$ & 470 & 1118 & $0.10(0.01)$ & 1.1 \\
\hline \multirow{2}{*}{ H2 } & B1 & $516(58)$ & 431 & 671 & $0.09(0.01)$ & 1.0 \\
\cline { 2 - 8 } & B2 & $657(110)$ & 480 & 1848 & $0.08(0.01)$ & 1.0 \\
\hline \multirow{2}{*}{ H3 } & B1 & $719(176)$ & 513 & 1715 & $0.15(0.06)$ & 0.7 \\
\cline { 2 - 8 } & B2 & $1409(255)$ & 657 & 2272 & $0.01(0.00)$ & 0.3 \\
\hline H4 & B1 & $593(57)$ & 447 & 800 & $0.11(0.06)$ & 0.5 \\
\hline H5 & B1 & $658(35)$ & 547 & 749 & & 0.3 \\
\hline H6 & B1 & $705(88)$ & 565 & 905 & $0.06(0.01)$ & 0.4 \\
\hline
\end{tabular}

\subsection{Periods with high $\mathrm{CO}_{2}$ levels}

In $\mathrm{H} 1 \mathrm{~B} 1$ and $\mathrm{H} 3 \mathrm{~B} 2$, the $\mathrm{CO}_{2}$ concentration exceeded $950 \mathrm{ppm}$, respectively, 80 and $70 \%$ of the time during the nights. In the other bedrooms the concentration exceeded $950 \mathrm{ppm}$ for smaller periods and the percentage was around $10 \%$ or lower.

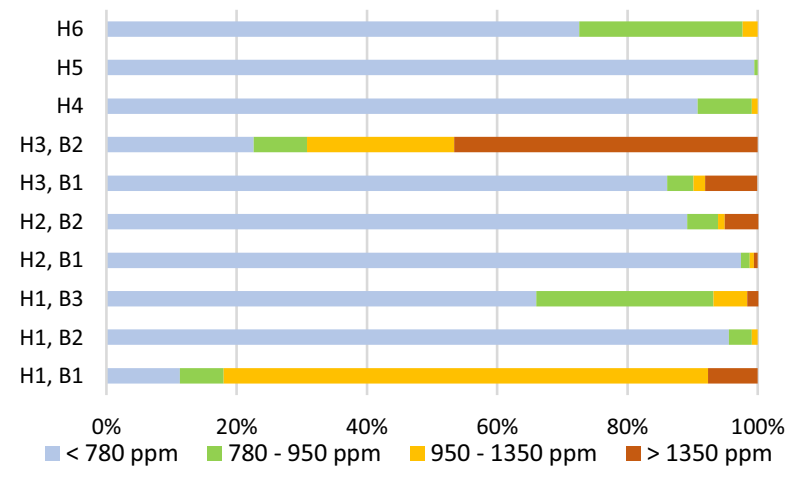

Figure 3. Time duration of $\mathrm{CO}_{2}$ concentration at night, distributed in the four IEQ categories [7].

\subsection{Variation in $\mathrm{CO}_{2}$ levels during the measurement period}

In most of the bedrooms a clear daily pattern in the $\mathrm{CO}_{2}$ levels could be seen. In H1B1 there was a similar rise in $\mathrm{CO}_{2}$ every night, when occupied by two adults. The concentration decreases rapidly in the morning and reaches almost the outdoor level during the day. In this bedroom, the window was constantly open but heavy curtains were in use during the night.

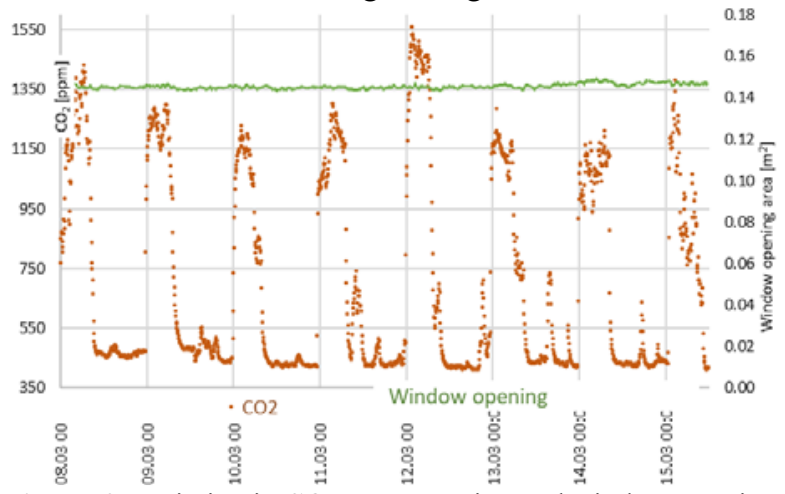

Figure 4. Variation in $\mathrm{CO}_{2}$ concentration and window opening area of bedroom H1B1.

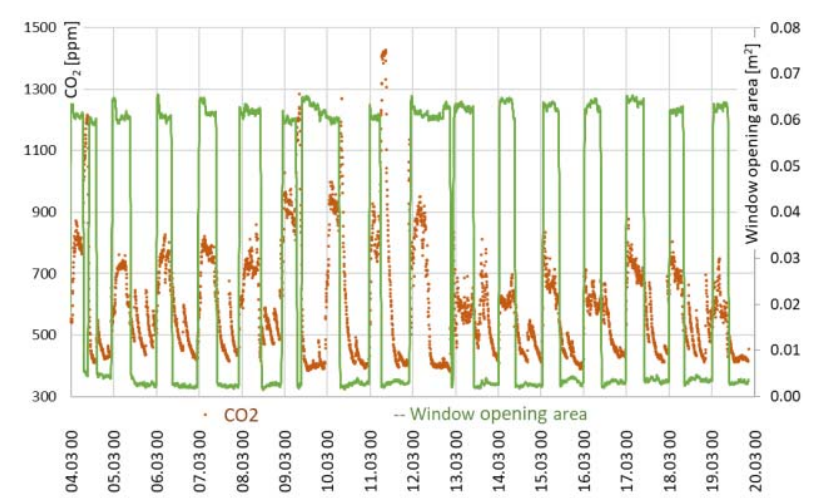

Figure 5. Variation in $\mathrm{CO}_{2}$ concentration and window opening area in house 6 . Two occupants sleeping in the bedroom until 12.03 .

Case house 6 also had the window open during the daytime for some days (Fig. 5). It should also be noted how the concentration decreases during the day, when the window is closed. This indicates an unoccupied room with sufficient ventilation through vents or infiltration. 


\subsection{Higher daytime $\mathrm{CO}_{2}$ concentrations}

For some bedrooms, levels were higher during the day (afternoon and evening), when windows were closed. Low night-averaged concentrations were found in bedroom 2 and 3 of case house 1, where two children were sleeping. Figure 6 illustrates how the concentration decreases rapidly when the window is opened at night. The occupants seem to follow the regular habit of opening the window when going to bed, and it seems like this opening is sufficient for good IAQ at night. The window in room 2 generally has a larger opening, and this room also has a lower $\mathrm{CO}_{2}$ concentration. We can also see that the concentration increases a bit during the day, when the window is closed. The concentration is often highest in the afternoon and evening, probably due to occupation. Both rooms are used by children/teenagers.

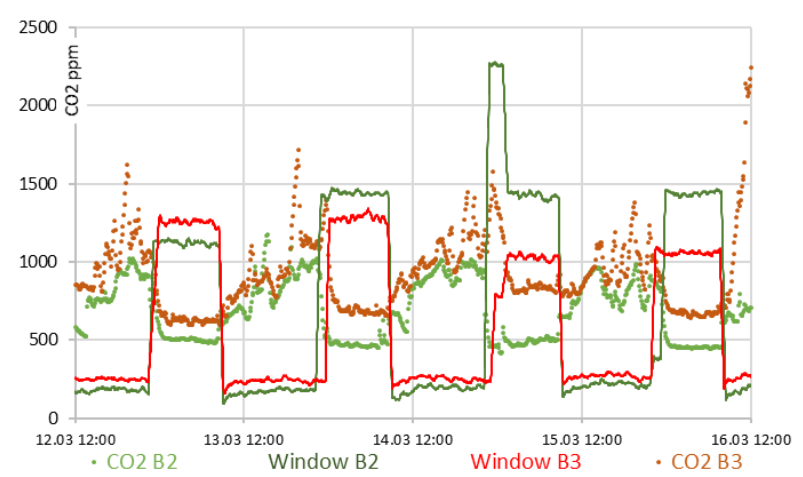

Figure 6. Variation of $\mathrm{CO}_{2}$ concentration and window opening area of bedroom H1B2 and H1B3.

\subsection{PM, TVOC and FH}

The average concentrations of PM were found to be low and well-below the WHO guideline limit for most of the bedrooms. The highest values of VOC, FH and PM were seen when rooms were occupied and the window closed. High values were found in childrens and teenagers' rooms. Many of the peaks occur just before window opening, and are most likely related to occupant behaviour.

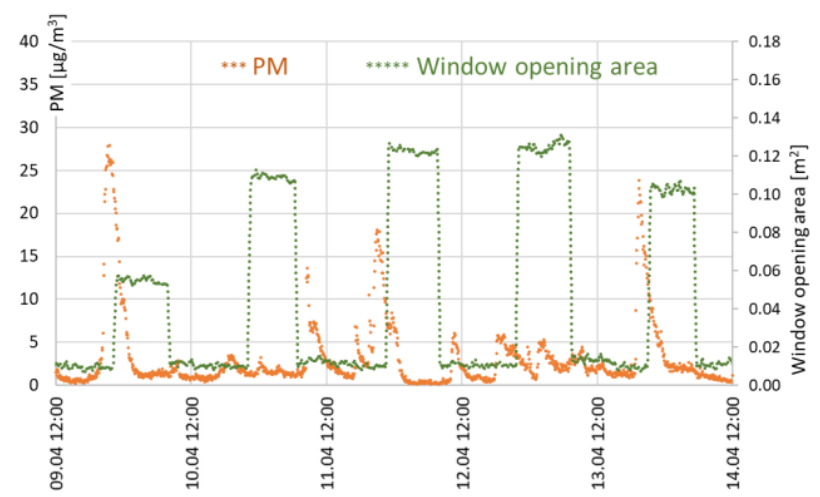

Figure 7. Variation of PM and window opening area in bedroom H2B2.

\section{Discussion}

\subsection{Selections of houses and occupants}

This study targets inhabitants who has a habit of opening the bedroom window during night-time. In addition, the study considers building with a tight envelope. Therefore, a selection bias may be present in the chosen buildings and inhabitants. The results may therefore not be transferable to dwellings or inhabitants, in general.

\subsection{Window opening area}

During the tests and the field investigations, the accelerometer was found to be a good solution for measuring the opening angle of bottom- and top-hinged windows. Accuracy was estimated to be 2 degrees, clearly sufficient for a qualitative assessment of the window ventilation. Unfortunately, this method does not work on side-hinged windows.

Airflow through window openings are not only affected by the area, but also details of shape and construction. Other factors like windspeed and direction, temperature difference between indoor and outdoor, opening height and curtain configuration also determines the air flow through the window

\subsection{IAQ measurements}

Due to lack of thorough validation and calibration, the accuracy of IAQ sensors measuring FH and TVOC could not be confirmed. During the set-up of the equipment, it was not always possible to place sensors optimally in the bedroom. Some measurements may show local values close to the sensor and may not be representative for the IAQ in the entire room. The average IAQ during the night is calculated between 23:00 and 06:00, without taking individual differences into account. If real occupancy deviates from this, inaccuracies may occur.

\subsection{Infiltration}

The monitored houses are assumed to have relatively low infiltration, as they are all renovated. The large increase in $\mathrm{CO}_{2}$ concentrations when rooms are occupied without open window confirms a low infiltration, as shown in Fig. 6 and 8. In future work, the infiltration rates need to be evaluated quantitatively.

\subsection{Window opening behaviour}

The window opening behaviour was shown to be both predictable and continuous. The bedroom windows were opened every night in almost all the bedrooms. It seemed like many occupants had a habit of opening the window when going to bed. Two of the ten bedrooms ( $\mathrm{H} 3 \mathrm{~B} 2$ and $\mathrm{H} 1 \mathrm{~B} 1)$ were found to have high $\mathrm{CO}_{2}$ concentration during night-time. In these two bedrooms, 
the window had a small opening kept during day and night, but the opening was not increased during the night. This opening seems insufficient during nigh-time, and maybe larger than necessary at daytime, when there is no occupation.

In the other eight bedrooms the window opening seemed to be adequate to keep the $\mathrm{CO}_{2}$ concentration low during night-time. For some rooms, a correlation between window opening and $\mathrm{CO}_{2}$ concentration was seen (see Figs. 6 and 8), but this could not be established as a general rule.

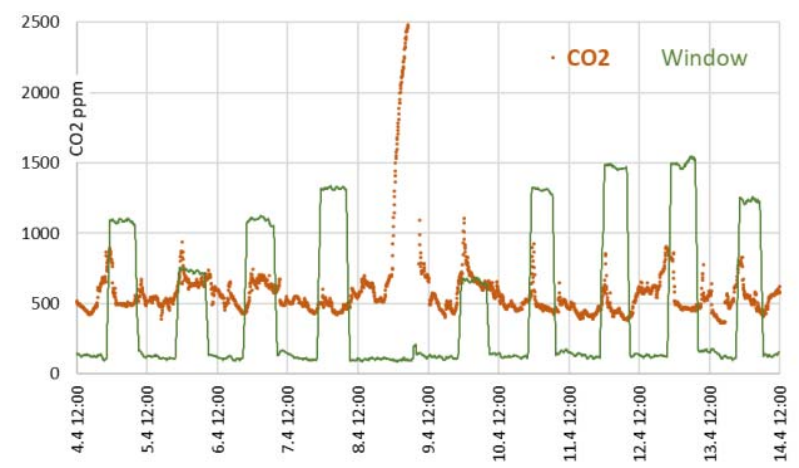

Figure 8. Variation of $\mathrm{CO}_{2}$ concentration and window opening area of bedroom $\mathrm{H} 2 \mathrm{~B} 2$.

\subsection{IAQ values during daytime occupation}

In some of the bedrooms the concentration was higher in the afternoon and evening, than at night. This often seemed to be the case in bedrooms of children and young adults, for instance H1B2 and H1B3. The explanation is likely to be occupation with a closed door and window. This indicates how the occupancy of the room during the day should be taken into consideration when natural ventilation is used in a bedroom (illustrated in Fig. 6 and 8).

The monitored rooms can be divided into two main groups: the "pure" bedrooms, and the multi-activity rooms (sleeping, homework, play, gaming etc.). The "pure" bedrooms seem to have the highest $\mathrm{CO}_{2}$ concentrations at night, simply because they are occupied only during the night. The multi-activity rooms often have the highest $\mathrm{CO}_{2}$ concentrations during daytime, probably due to occupation with the window (and door) closed. In most cases the concentration decreases as the window is opened when going to sleep. These rooms are typically used by children or teenagers.

\subsection{Factors reducing window opening}

When occupants were asked for reasons for not opening the window at night, low indoor or outdoor temperature was the most common answer. The monitoring slightly confirms this statement: in two of the bedrooms there were two nights with the window closed, at low outdoor temperatures. These temperatures were, however, hardly below $-5^{\circ}$. Windows may be less open in colder periods, but it is not determined at which outdoor temperature the effect starts to occur, and this may also differ strongly between the individuals.
Less extensive window opening during the coldest months may lead to more nights of lower IAQ. However, if the window is still opened during the colder months but with a smaller opening, the IAQ in the bedroom may not be lower (due to stronger driving forces caused by higher temperature difference between indoor and outdoor).

\subsection{Hybrid system}

In one of the studied houses, the bedrooms had natural ventilation and the rest of the house had balanced mechanical ventilation. During one night, the window was not opened, resulting in high $\mathrm{CO}_{2}$ levels. A very rapid decrease in $\mathrm{CO}_{2}$ concentration was recorded in the morning, probably due to airflow from other parts of the building when the bedroom door was opened (Fig. 8). If this assumption is right, it may indicate how this kind of hybrid ventilation system could provide a low concentration of $\mathrm{CO}_{2}$ during daytime, with the door open.

\subsection{Temperature and RH}

In six out of ten bedrooms, the daily-averaged temperature was below $18^{\circ} \mathrm{C}$ while, in the remaining four bedrooms, the average was above $21^{\circ} \mathrm{C}$. The "cooler" rooms had no local heating, and a correlation between the outdoor and indoor temperature was observed. These measurements confirmed that many occupants prefer a lower bedroom temperature. It indicates the importance of considering individual preferences when the indoor environment in bedrooms are evaluated.

The RH levels seemed to correlate to the outdoor temperature in most rooms, with some delay as illustrated in Fig. 9. The four "warm" rooms showed lower RH. Three of them have a minimum nightlyaveraged $\mathrm{RH}$ below $20 \%$, which is lower than recommended. The "cooler" rooms had a nightlyaveraged RH between 32 and 49\%, the highest maximum nightly-averaged RH being $57 \%$. If such a high $\mathrm{RH}$ is combined with cold thermal bridges and interior surfaces (with low ability to transport moisture), this could cause mould problems. Our case houses are however renovated and well insulated.

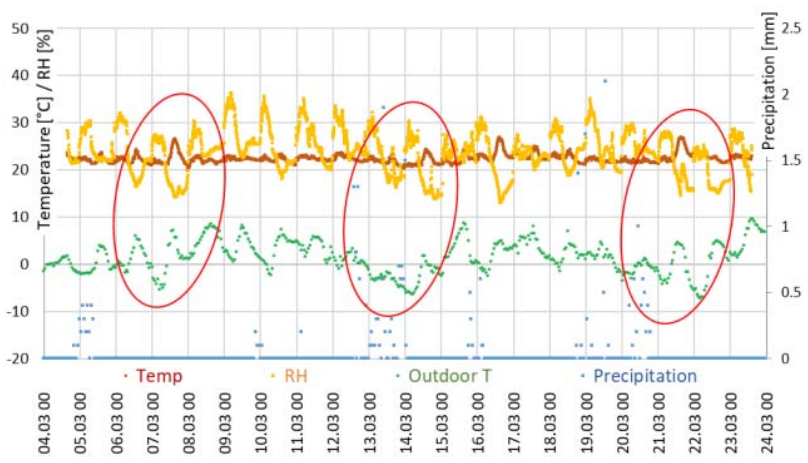

Figure 9. Temperature and RH level in H1B1 compared to outdoor temperature and precipitation 


\section{Conclusions}

The indoor temperature and IAQ was measured in the ten bedrooms ventilated using window opening in renovated houses. The window opening behaviour was shown to be both predictable and continuous. The bedroom windows were found to be open every night in almost all the bedrooms. High $\mathrm{CO}_{2}$ levels at night were however found in two bedrooms. In the other bedrooms, $\mathrm{CO}_{2}$ concentration was at a satisfying level during the nighttime. This suggests that it is possible to achieve a high IAQ with manual window ventilation when this is a deliberate strategy, also in energy-renovated houses. In some rooms used for activities during daytime (like for children), the most unfavorable conditions were found during occupancy in daytime with the window closed.

The temperature measurements confirmed that many occupants may prefer a lower bedroom temperature and indicated the importance of considering individual preferences when the indoor environment in bedrooms are evaluated. Finally, the number of bedrooms investigated in this study is too limited to generalize the conclusions. In future work, measurements will be done in a larger set of bedrooms.

\section{References}

[1] B. Bjorvatn, J. Mrdalj, I. W. Saxvig, T. Aasnæs, S. Pallesen, and S. Waage, "Age and sex differences in bedroom habits and bedroom preferences," Sleep medicine, vol. 32, pp. 157-161, 2017.

[2] M. Berge and H. M. Mathisen, "Perceived and measured indoor climate conditions in highperformance residential buildings," Energy and Buildings, vol. 127, pp. 1057-1073, 2016.

[3] K. E. Thomsen et al., "Energy consumption and indoor climate in a residential building before and after comprehensive energy retrofitting," Energy and Buildings, vol. 123, pp. 8-16, 2016, doi:

10.1016/j.enbuild.2016.04.049.

[4] R. Andersen, V. Fabi, J. Toftum, S. P. Corgnati, and B. W. Olesen, "Window opening behaviour modelled from measurements in Danish dwellings," Building and Environment, vol. 69, pp. 101-113, 2013, doi: 10.1016/j.buildenv.2013.07.005.

[5] J. Fernández-Agüera, S. DominguezAmarillo, M. Fornaciari, and F. Orlandi, "TVOCs and PM 2.5 in Naturally Ventilated Homes: Three Case Studies in a Mild Climate," Sustainability, vol. 11, no. 22, p. 6225, 2019.

[6] (2016). Veiledning om klima og luftkvalitet på arbeidsplassen.

[7] NS-EN 16798-1 Energy performance of buildings - Ventilation for buildings, 2019.

[8] L. Øie, H. Stymne, C. A. Boman, and V. Hellstrand, "The ventilation rate of 344 Oslo residences," Indoor Air, vol. 8, no. 3, pp. 190196, 1998.

[9] S. Langer and G. Bekö, "Indoor air quality in the Swedish housing stock and its dependence on building characteristics," Building and Environment, vol. 69, pp. 44-54, 2013.

[10] (2010). WHO Guidelines for indoor air quality: selected pollutants.

[11] C.-G. Bornehag, J. Sundell, L. HägerhedEngman, and T. Sigsgaard, "Association between ventilation rates in 390 Swedish homes and allergic symptoms in children," Indoor air, vol. 15, no. 4, pp. 275-280, 2005.

[12] G. Bekö, T. Lund, F. Nors, J. Toftum, and G. Clausen, "Ventilation rates in the bedrooms of 500 Danish children," Building and Environment, vol. 45, no. 10, pp. 2289-2295, 2010.

[13] M. Kotol, C. Rode, G. Clausen, and T. R. Nielsen, "Indoor environment in bedrooms in 79 Greenlandic households," Building and Environment, vol. 81, pp. 29-36, 2014.

[14] D. Aubin et al., "Effectiveness of ventilation interventions at improving indoor air quality in Canadian homes with asthmatic children," in Proceedings of Healthy Buildings, 2012.

[15] T. Sharpe, C. Porteous, J. Foster, and D. Shearer, "An assessment of environmental conditions in bedrooms of contemporary low energy houses in Scotland," Indoor and Built Environment, vol. 23, no. 3, pp. 393-416, 2014.

[16] N. Shinohara, T. Kataoka, K. Takamine, and M. Gamo, "Distribution and variability of the 24-h average air exchange rates and interzonal flow rates in 26 Japanese residences in 5 seasons," Atmospheric environment, vol. 45, no. 21, pp. 3548-3552, 2011.

[17] S. Ilomets, T. Kalamees, and J. Vinha, "Indoor hygrothermal loads for the deterministic and stochastic design of the building envelope for dwellings in cold climates," Journal of Building Physics, vol. 41, no. 6, pp. 547-577, 2018.

[18] L. Du et al., "Air change rates and interzonal flows in residences, and the need for multizone models for exposure and health analyses," International journal of environmental research and public health, vol. 9, no. 12, pp. 4639-4661, 2012.

[19] J. Hou et al., "Air change rates in residential buildings in Tianjin, China," Procedia Engineering, vol. 205, pp. 2254-2258, 2017.

[20] J. Park, N. Y. Jee, and J. W. Jeong, "Effects of types of ventilation system on indoor particle concentrations in residential buildings," Indoor Air, vol. 24, no. 6, pp. 629-638, 2014.

[21] S. Langer, G. Bekö, E. Bloom, A. Widheden, and L. Ekberg, "Indoor air quality in passive and conventional new houses in Sweden," Building and Environment, vol. 93, pp. 92100, 2015. 
[22] R. V. Jones, A. Fuertes, E. Gregori, and A. Giretti, "Stochastic behavioural models of occupants' main bedroom window operation for UK residential buildings," Building and Environment, vol. 118, pp. 144-158, 2017. [Online]. Available: http://hdl.handle.net/10026.1/8698

[23] M. Berge, L. Georges, and H. M. Mathisen, "On the oversupply of heat to bedrooms during winter in highly insulated dwellings with heat recovery ventilation," J Building Environment, vol. 106, pp. 389-401, 2016.

[24] S. Verbruggen, M. Delghust, J. Laverge, and A. Janssens, "Window use habits in Belgian households " presented at the The 16th Conference of the International Society of Indoor Air Quality \& Climate 2020.

[25] M. G. Bjørneboe, S. Svendsen, and A. Heller, "Evaluation of the renovation of a Danish single-family house based on measurements," Energy and Buildings, vol. 150, pp. 189-199, 2017, doi: 10.1016/j.enbuild.2017.04.050.

[26] D. Liu, Z. Ren, S. Wei, Z. Song, P. Li, and X. Chen, "Investigations on the Winter Thermal Environment of Bedrooms in Zhongxiang: A Case Study in Rural Areas in Hot Summer and Cold Winter Region of China," Sustainability, vol. 11, no. 17, p. 4720, 2019.

[27] M. institutt. "Norsk Klimaservicesenter." https://seklima.met.no/observations/ (accessed.

[28] S. Skyttern, "Assessment of the indoor environment in bedrooms of existing Norwegian dwellings," Master thesis, NTNU, 2020.

[29] O. K. Gram, "Use of low cost pollutant sensors for developing healthy demand controlled ventilation strategies-A case study in four primary school classrooms," Master thesis, NTNU, 2019.

[30] T. B. Jørgensen, "Utilizing IoT technology for healthy and energy efficient improvement of existing ventilation systems. Case study of indoor air quality in a primary school classroom using Arduino sensors and CONTAM simulations," Master thesis, NTNU, 2020.

[31] "BBC micro:bit." https://tech.microbit.org/hardware/\#hardwaredescription (accessed. 